\title{
Bailout Strategies and Complications Associated with the Use of Flow-Diverting Stents for Treating Intracranial Aneurysms
}

\author{
Fawaz Al-Mufti ${ }^{a}$ b Eric R. Cohen ${ }^{a}$ Krishna Amuluru ${ }^{c}$ Vikas Patel $^{a}$ \\ Mohammad El-Ghanem $^{d}$ Rolla Nuoman $^{\text {e Neil Majmundar }}{ }^{b}$ \\ Neha S. Dangayach $^{f}$ Philip M. Meyers ${ }^{g}$ \\ a Department of Neurology and Neurosurgery, Westchester Medical Center at New York \\ Medical College, Valhalla, NY, USA; ${ }^{b}$ Departments of Neurology and Neurosurgery, \\ Rutgers University - Robert Wood Johnson Medical School, New Brunswick, NJ, USA; \\ 'Department of Neurointerventional Radiology, University of Pittsburgh-Hamot, Erie, PA, \\ USA; ${ }^{d}$ Department of Neurology and Medical Imaging, University of Arizona College of

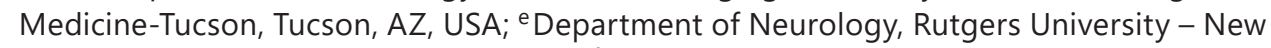 \\ Jersey Medical School, Newark, NJ, USA; ' Departments of Neurology and Neurosurgery, \\ Icahn School of Medicine at Mount Sinai, New York, NY, USA; 9 Departments of Radiology \\ and Neurosurgery and Columbia University Medical Center, New York, New York, NY, USA
}

\section{Keywords}

Flow diversion - Cerebral aneurysms · Periprocedural complications · Endovascular management $\cdot$ Diverting stent

\begin{abstract}
Background: Flow-diverting stents (FDS) have revolutionized the endovascular management of unruptured, complex, wide-necked, and giant aneurysms. There is no consensus on management of complications associated with the placement of these devices. This review focuses on the management of complications of FDS for the treatment of intracranial aneurysms. Summary: We performed a systematic, qualitative review using electronic databases MEDLINE and Google Scholar. Complications of FDS placement generally occur during the perioperative period. Key Message: Complications associated with FDS may be divided into periprocedural complications, immediate postprocedural complications, and delayed complications. We sought to review these complications and novel management strategies that have been reported in the literature.

(c) 2018 S. Karger AG, Basel
\end{abstract}




\section{Introduction}

The introduction of flow-diverting stents (FDS) has provided a promising alternative option for the repair of giant-size, wide-neck, and fusiform aneurysms that have historically been challenging [1-9]. Flow diversion carries a high risk of thromboembolic complications; hence, platelet inhibition is recommended to reduce the risk of thromboembolic events [10]. The mechanism of action of flow-diverting stents is based on two concepts: (1) the disruption of blood flow from the parent artery into the aneurysm and (2) the provision of a scaffold on which endothelial cells can grow. These two actions isolate the aneurysm from the parent artery by causing remodeling or "reconstruction" around the prosthesis while eliminating the aneurysm-parent vessel interface altering flow dynamics both across and within, the cerebral aneurysm, leading to thrombosis [6,11-23]. Risks associated with FDS may be divided into periprocedural complications, immediate postprocedural complications, and delayed complications. Herein, we sought to review these complications and their respective management strategies.

\section{Methods}

A systematic, qualitative review of the literature for relevant, peer-reviewed articles up to May 1, 2017, was performed. Electronic databases MEDLINE and Google Scholar were mined using Boolean operators "AND" and "OR" for search terms "flow diverter," "endovascular," "aneurysm," "intracranial," and "pipeline" in various combinations. The search and the retrieved citations were examined in their entirety by 4 authors (FA, E.R.C., K.A., and V.P.) independently by reviewing article title, abstract and full-texts. Bibliographies of identified citations and articles citing them were also examined. All studies including case reports, case series, clinical trials, or observational cohorts were included in this review if they addressed any questions related to the management of FDS. Further criteria for article selection relied upon the description of complication in the identified publications. Studies or reports describing the use of FDS for treatment procedures other than intracranial aneurysms were excluded. Any potential conflict on article selection was mitigated by discussion and mutual consensus with arbitration by the senior authors (F.A. \& P.M.M.). Based on the focus of our review, complications of use of FDS for aneurysm treatment were categorized as (1) periprocedural or (2) postprocedural.

\section{Results}

\section{Periprocedural Complications}

Periprocedural complications increase morbidity and should be identified quickly and even anticipated so that they can be prevented, or at least quickly identified and corrected. We categorize these periprocedural complications into four categories: (1) thromboembolic/ ischemic events, (2) side branch occlusions, (3) parent artery injury and/or rupture, and (4) malposition or migration of the flow-diverting stent(s).

Thromboembolic and Ischemic Complications

Thromboembolic complications in the setting of flow diversion include acute and hyperacute stent thrombosis, large-vessel occlusion, and perforator or side-branch occlusion. The incidence of symptomatic thromboembolic complications has been reported in various studies to be between 2 and 8\% [24-29], similar to reported complication rates experienced with coil embolization [30-32]. Interestingly, the frequency of asymptomatic ischemic events associated with use of FDS, as detected by postprocedural diffusion-weighted imaging (DWI), was higher than similar events with coiling in two separate cohorts: $63 \%$ asymptomatic 
events according to Brasiliense et al. [24] and 50.9\% according to Tan et al. [28]. However, these results should be interpreted with caution, since silent infarcts are a known consequence of diagnostic coronary and cerebral angiography alone [33, 34]. Nevertheless, as Tan et al. [28] noted, DWI changes occurred at a nearly 6-fold higher rate than clinical symptoms. Symptomatic thromboembolism was associated with longer procedure time ( $>116 \mathrm{~min}$ ) and deployment of more than one flow-diverting device, suggesting this complication is more common with complex aneurysms or tortuous vascular anatomy.

Therapeutic dual antiplatelet therapy must be initiated in preprocedurally to prevent thromboembolic and ischemic complications. Some individuals show genetic variation resulting in failure to respond to commonly used antithrombotic agents such as clopidogrel. Moreover, certain medications may inhibit antithrombotic activity of certain antiplatelet agents [35]. There is no consensus on the best method to determine adequate preprocedure drug response [36, 37]. Point of service testing devices can be imprecise or inaccurate, and there has been temporal variation in test results. For this reason, some experts have advocated genetic testing [38]. Some operators do not test for drug effect on platelet aggregation. Follow-up angiographic runs should be performed frequently to assess for filling defects in the parent artery and stent, and for disappearance of perforator side branches, especially during complex cases. Finally, using effective heparinization during the case, and having glycoprotein (GP) IIb/IIIa receptor antagonist medications readily available is critical.

(1) GP IIb/IIIa Inhibitors. Hyperacute and acute thrombi are platelet-rich (so-called "white thrombus"), hence intravenous antiplatelet medications are a first-line approach and theoretically better suited than fibrinolytics for the management of intraprocedural thrombosis $[39,40]$. The three FDA-approved GP IIb/IIIa receptor antagonists - abciximab (ReoPro, Eli Lilly Inc.), tirofiban (Aggrastat, Medicure International Inc.), and epitifibatide (Integrilin, Millenium Pharmaceuticals Inc.) - are potent inhibitors of both platelet cross-linking and aggregation and are well-suited for periprocedural clot disruption [41].

Abciximab has the most widely reported use as a thromboembolic rescue therapy during neuroendovascular procedures [26, 42]. Based on use in the coronary circulation, abciximab is meant to be administered intravenously (IV), beginning with a rapid bolus at a weightbased dose of $0.25 \mathrm{mg} / \mathrm{kg}$, followed by a continuous maintenance infusion of $125 \mu \mathrm{g} / \mathrm{kg} / \mathrm{min}$ (to a maximum of $10 \mathrm{mg} / \mathrm{min}$ ) for $12 \mathrm{~h}$ [43]. Anecdotally, many neurointerventionalists report successful application of abciximab as an intra-arterial bolus, with the catheter tip directed at or within the obstructing thrombus, rather than as an IV bolus [39] and often using smaller doses than conventional loading doses based on weight and volume of distribution. In a small series of retrospectively reviewed cases, Song et al. [39] noted that immediate thrombolysis was achieved with a much lower dose bolus of abciximab when it was delivered intra-arterially (IA), directly at the thrombus, than when it was administered IV [44]. Early treatment of endoluminal thrombi in an FDS before significant vessel stenosis or complete occlusion occurs should be considered, as patients with luminal narrowing following deployment of an FDS are at higher risk of complete in-stent thrombosis [42].

Eptifibatide is also administered as either an IA or IV bolus at a dose of $180 \mu \mathrm{g} / \mathrm{kg} \mathrm{[41,}$ $45]$. This may be followed with a maintenance infusion rate of $2 \mu \mathrm{g} / \mathrm{kg} / \mathrm{min}$ for $20-24 \mathrm{~h}$ at the discretion of the operator [45]. Tirofiban is infused at an initial rate of $0.4 \mu \mathrm{g} / \mathrm{kg}$ over $30 \mathrm{~min}$ or more followed by infusion at a rate of $0.1 \mu \mathrm{g} / \mathrm{kg}$ over several hours. It should be mentioned at this point that these doses have been extrapolated from the cardiology literature, and formal studies in patients with FDS are currently lacking.

Intracranial hemorrhage (ICH) is one of the risks associated with the use of any GP IIb/ IIIa inhibitors, and the rate of this complication is higher in patients undergoing endovascular treatment of ruptured aneurysms [46]. Abciximab has a prolonged platelet inhibitory effect which can persist for 8-15 days after infusion of the drug has been discontinued [47]. This 
may be overcome with platelet transfusion, thus making it the preferred drug by many operators [47]. Furthermore, paradoxical drug-induced platelet activation has been observed with abciximab when lower than adequate levels of platelet inhibition are achieved [48]. Thrombocytopenia is a rare complication of abciximab use and thus platelet levels should be measured before administration, and monitored thereafter [49].

Eptifibatide and tirofiban have relatively short durations of action, with biological halflives of 2-4 $\mathrm{h}$ for eptifibatide and 1.5-2 $\mathrm{h}$ for tirofiban [41]. Clearance of eptifibatide and tirofiban is predominantly renal, and while renal function remains normal, the platelet inhibitory effect of eptifibatide and tirofiban will be minimal several hours after discontinuing and infusion [47]. In cases of renal insufficiency, the doses should be adjusted [49]. While some authors mention platelet transfusion as a potential reversal mechanism for eptifibatide and tirofiban, such measures are ineffective as the circulating drug will simply inactivate the transfused platelets [49]. Here, the trade-off is a relatively short half-life but limited ability to reverse the effect in a neurological emergency. For these reasons, all GP2b3a inhibitors must be used with great care and trepidation.

(2) Fibrinolytics. IA fibrinolytics, such as recombinant tissue plasminogen activator and urokinase have been used to treat intra-arterial thrombus formation during endovascular aneurysm treatment, as their short half-lives make them well-suited for this application [50, 51]. However, in theory, these drugs may not be as effective as antiplatelet agents such as the GP IIb/IIIa inhibitors in disrupting an acute, platelet-rich thrombus. Like the GP IIb/IIIa inhibitors, thrombolytics carry a risk of ICH, which may particularly limit their use in the setting of ruptured aneurysm treatment. If the thrombus is occluding the parent artery or stent, mechanical disruption may be helpful in loosening the thrombus material and creating more surface area on which the antiplatelet or thrombolytic drug may act, similar to the technique advocated by Cronqvist et al. [51].

(3) Mechanical Thrombectomy. Mechanical thrombectomy may theoretically be used to recanalize an acutely thrombosed FDS. (see Fig. 2) De Vries et al. [42] reported success with this approach in a single case within a larger series, although technical details regarding the rescue procedure were not delineated. Further studies are needed to demonstrate the safety of mechanical thrombectomy with regard to the theoretical risk of disrupting the flowdiverting construct, the risk of downstream embolization, and appropriate choice of mechanical thrombectomy device.

Conservative measures, such as intravascular volume expansion and blood pressure augmentation, have been a used occasionally for dealing with periprocedural thromboembolic complications and may be implemented concurrently with chemical and mechanical clot disruption $[41,52]$.

Side Branch Occlusion

Despite great concern over the possibility of side-branch occlusion, this complication seems to occur fairly infrequently, with one study reporting a rate as low as $1.4 \%$ (i.e., 2 out of 140 cases) at 6-month follow-up, and tends to be clinically silent [53]. Higher rates of occlusion were reported in a smaller case series [54] and have been discussed in case reports and reviews [27, 42]. Side-branch occlusion is generally believed to occur more frequently when two or more overlapping stents cover the origin of a branch artery [54]. However, sidebranch occlusion can occur following application of one device alone. Operators should carefully consider the risks and benefits of important branch vessel occlusions during FDS placement because study results remain inconclusive and its occurrence sporadic.

Side-branch occlusion seems to occur more commonly in the posterior circulation than the anterior circulation [55-57]. De Vries et al. [42] reported absence of anterograde flow on 6-month follow-up after Surpass implantation in 2 out of 15 cases of covered ophthalmic 
arteries $(15 \%)$ and 4 out of 15 cases of covered posterior communicating arteries (31\%), fortunately without neurological symptoms. Side-branch occlusion has been associated with placement of multiple overlapping flow diverters, since the porosity of the barrier between the parent artery and the branch vessel is greatly reduced in areas where the stents are overlapping [54]. In addition to adequate antiplatelet preparation, parsimonious use of individual flow-diverting devices during completion of the stent-construct may be the greatest preventative measure. Nevertheless, in the event of an acutely occluded side branch after deploying an FDS, IA abciximab has been shown to be effective in recanalization [27].

Parent Vessel Perforation or Injury

Iatrogenic vascular injury in the setting of flow diversion has been reported in two scenarios: during initial deployment of an FDS and during attempted balloon remodeling of an incompletely expanded FDS. The spectrum of clinical consequences may range from minor to catastrophic. Arterial wire perforations that occur during FDS deployment or attempted deployment ultimately resulted in more favorable clinical outcomes than the vascular ruptures that occurred during attempted angioplasty of incompletely expanded stents [14, $26,42,58,59]$. Careful monitoring of the distal tip of the delivery wire to avoid placement in small and angulated vessels and gentle manipulation of the FDS may be the best defense against this type of complication [44]. Balloon test occlusion (BTO) prior to attempting flow diversion has been suggested by one group of authors if procedural challenges are anticipated based on difficult vascular anatomy [60]; however, BTO as a procedure has its own risk profile that is beyond the scope of this review.

(1) Arterial Perforation. Arterial perforation may not be immediately apparent unless contrast injection with image acquisition is performed at the time it occurs. For this reason, it is important that the operating physician is vigilant for other clinical evidence that such an event has occurred. An abrupt increase in systemic blood pressure and concomitant bradycardia (Cushing reflex), or a sudden rise in intracranial pressure (ICP), are hallmark signs of acute ICH. Extravasation of contrast should be immediately confirmed by angiography and the site of perforation identified. However, multiple angiographic runs should be avoided, as they waste critical time and deposit additional contrast in the subarachnoid space which can lead to malignant intracranial hypertension and other consequences [61,62]. Late in the process, increased arteriovenous transit time due to elevated intracranial pressure or even mass-effect from a growing hematoma may become apparent on the arteriogram.

A key step in the management of iatrogenic ICH is immediate reversal of anticoagulation [63]. As in any intraoperative arterial perforation in neurointerventional procedures in general, the effect of heparin is reversed with protamine sulfate [61]. Platelet transfusion [63] and stringent blood pressure control are also recommended. Placement of a ventriculostomy in the presence of high-level antithrombotic medication increases the risk of this procedure; however, reversal of all antithrombotic medication effect can cause intravascular thrombosis, thus creating an important management dilemma for which no consensus currently exists.

If the vascular perforation is minor and occurs prior to deployment of the FDS, or at a point when the FDS can still be re-sheathed, conservative measures such as those described above may be sufficient. In a series of 37 patients treated with the Surpass flow diverter, De Vries et al. [42] reported one case of a wire perforation of the middle cerebral artery (MCA) resulting in an acute subarachnoid hemorrhage (SAH) prior to deployment of the FDS. Heparin and antiplatelet medications were promptly reversed, and there were no clinical consequences. During any procedure, it is important that the operator always pays attention to the position of the guidewire.

Some neurointerventionalists advocate leaving the perforating device in place until the source of bleeding has been controlled. In these cases, the device itself may limit blood loss 

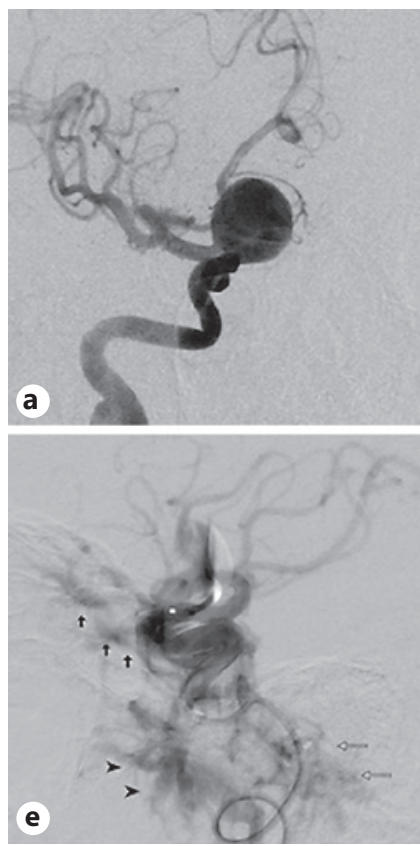
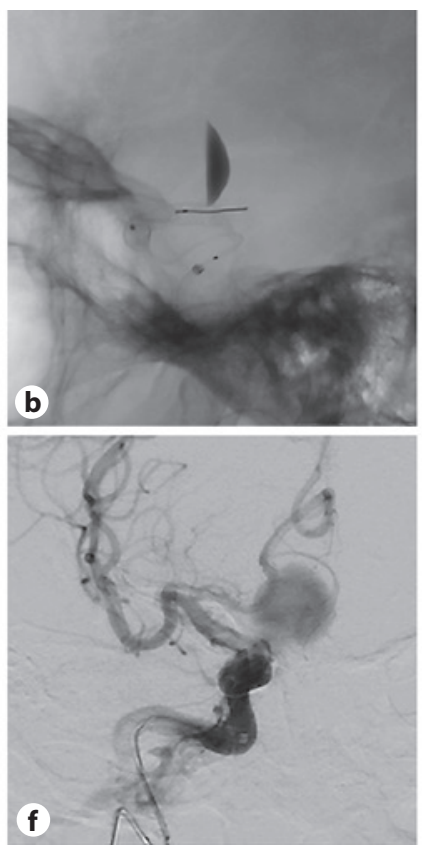
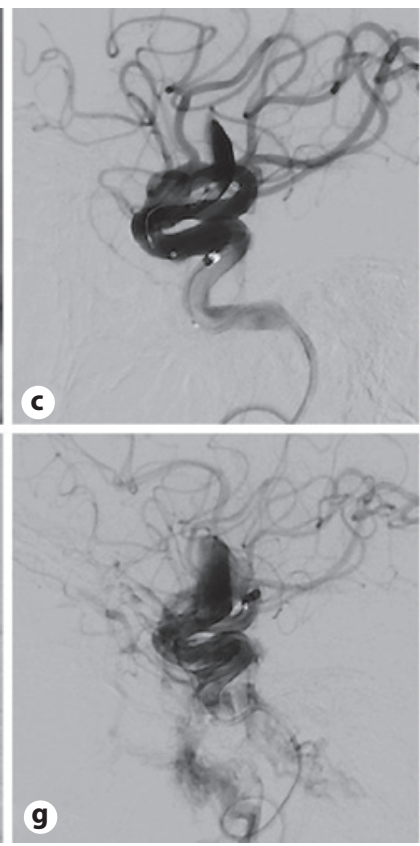
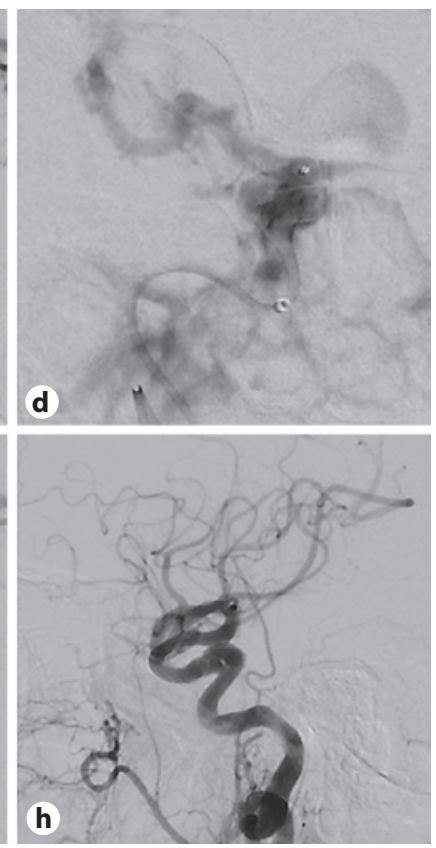

Fig. 1. a Digital subtraction angiogram (DSA) shows a large wide-necked unruptured paraclinoid right internal carotid artery (ICA) aneurysm. b Unsubtracted lateral view immediately after Pipeline embolization device (PED) \#1 shows contrast stagnation in aneurysm and apposition of PED to parent ICA. c DSA of right ICA in lateral view immediately after PED \#1 shows patent anterograde flow and no evidence of carotid-cavernous fistula (CCF). Subsequent DSA of the right ICA in frontal (d) and lateral (e) views shows decreased anterograde flow and development of CCF with retrograde flow anteriorly through the superior ophthalmic vein (arrows), inferiorly to the pterygoid plexus (arrowheads) and clival plexus (open arrows). After deployment of four additional PEDs, DSA of the right ICA in frontal (f) and lateral (g) views shows improved anterograde flow and decreased filling of CCF. $\mathbf{h}$ 12-month follow-up DSA of the right ICA in lateral view shows vessel reconstruction with resolution of CCF.

through the perforation, whereas withdrawing it may cause further damage to the vessel [61]. This is particularly applicable if perforation occurs in the aneurysm itself, in which case a second microcatheter may be placed to treat the rupture [64].

(2) Iatrogenic Carotid Cavernous Fistula. If the target lesion includes the cavernous ICA, vessel injury during FDS deployment or delayed rupture of the aneurysm after flow diversion may lead to the spontaneous development of a direct carotid cavernous fistula (CCF) (Fig. 1). The development of a direct (Barrow type A) CCF after flow diversion is rare, with 8 reported cases in the literature. It has been reported in acute and subacute timeframes after deployment of FDS [16, 65-69]. Management of an intraprocedural CCF after flow diversion is similar to traditional management of such etiologies, including transvenous embolization, parent artery sacrifice and operative methods such as surgical ligation $[65,70]$ or expectant management with ophthalmological evaluation as the guide to further intervention. However, transarterial embolization techniques of the cavernous sinus may be limited in certain cases of flow diversion within the cavernous ICA, since an already-deployed FDS may prevent transarterial access across the stent into the aneurysm or into the rupture site or fistulous connection (Fig. 1). The use of further flow diversion, for the treatment of direct CCFs that developed as a result of flow diversion, has been reported in few cases [69, 71-74]. In all but 2 of these cases, transarterial flow diversion was combined with concomitant transvenous emboli- 
zation of the ipsilateral cavernous sinus. Expeditious BTO of the ipsilateral ICA would aid in formulating treatment options.

Caution is mandated when employing balloon angioplasty to fully expand a partially opened or collapsed FDS. As noted with respect to the Pipeline embolization device (PED), a type of FDS, it is recommended that the balloon be completely maintained within the device when inflated rather than using the balloon to push the proximal device open, as the latter can result in arterial injury [44].

Sacrifice of the parent vessel is generally considered a last resort, and clinical outcome primarily depends on the specific vessel involved and the collateral blood supply to the affected region. Pistocchi et al. [58] reported one arterial perforation of the distal MCA in their series of 30 treated aneurysms, caused by the distal wire tip during deployment of a Silk flow diverter. The injured parent artery was immediately occluded by coil embolization without adverse clinical consequences. Historically, the interventional literature suggests a fairly high rate of cerebral infarction after surgical occlusion of the internal carotid artery without prior test occlusion [75].

In some cases, open surgical intervention may be necessary. Nelson et al. [76] reported one case of vascular rupture out of 31 patients treated in Pipeline (for the Intracranial Treatment of Aneurysms (PITA) trial [69]. The event occurred during an attempt to use angioplasty to correct the diminished flow observed in the parent ICA distal to an unsuccessfully deployed PED. The ruptured ICA required surgical ligation, and the patient suffered a large left-hemispheric infarct. Gentric et al. [59] reported a case of a recurrent MCA aneurysm, in which a SILK FDS (Balt Extrusion, Montmorency, France) was deployed through a cell of a previously implanted Solitaire AB stent (Covidien, Irvine, CA, USA). While attempting to perform balloon angioplasty in the proximal aspect of the partially opened stent, the parent vessel ruptured, resulting in a fatal hemorrhage. The authors retrospectively suggested that leaving the collapsed FDS in place and considering a surgical bypass may have been a better alternative.

(3) Arterial Dissection. Iatrogenic dissections, and their management, have been welldocumented in the vascular and interventional literature [77, 78]. Although no general consensus exists on the treatment of iatrogenic carotid dissections during flow diversion procedures, management of these injuries is governed by similar variables of historical data, including symptomatology, degree of stenosis, and operator preference, to name a few. De Vries et al. [42] reported 2 iatrogenic cervical ICA dissections in a study of the Surpass flow diverter, one of which was treated with further flow diversion. The other ICA dissection was missed at the time of the procedure and resulted in the occlusion of the vessel. Fischer et al. [79] and Brzezicki et al. [80] have demonstrated successful treatment of intracranial and cervical vascular dissections with PED. Although these studies did not address treatment of iatrogenic dissections, their results nevertheless support the notion of using flow-diverting devices for this purpose [81].

Incomplete Expansion, Migration, Prolapse, and Device Removal

Mechanical factors, particularly in the setting of tortuous vascular anatomy, creates an environment in which the FDS is prone to suboptimal deployment and overt technical failure compared to traditional self-expanding stents [82-84]. Moreover, a learning curve of 35-40 cases is associated with use of FDS, with the risk of complications decreasing as operators gain experience with the device [85].

For optimal results, operators should select an appropriate size for an FDS - the expanded diameter should be equivalent to the size of the proximal parent vessel and at least $6 \mathrm{~mm}$ longer than the aneurysm neck. Foreshortening of 50-60\% usually tends to occur and should be accounted for when selecting the size for an FDS. The device should be at least 2-3 $\mathrm{mm}$ at 

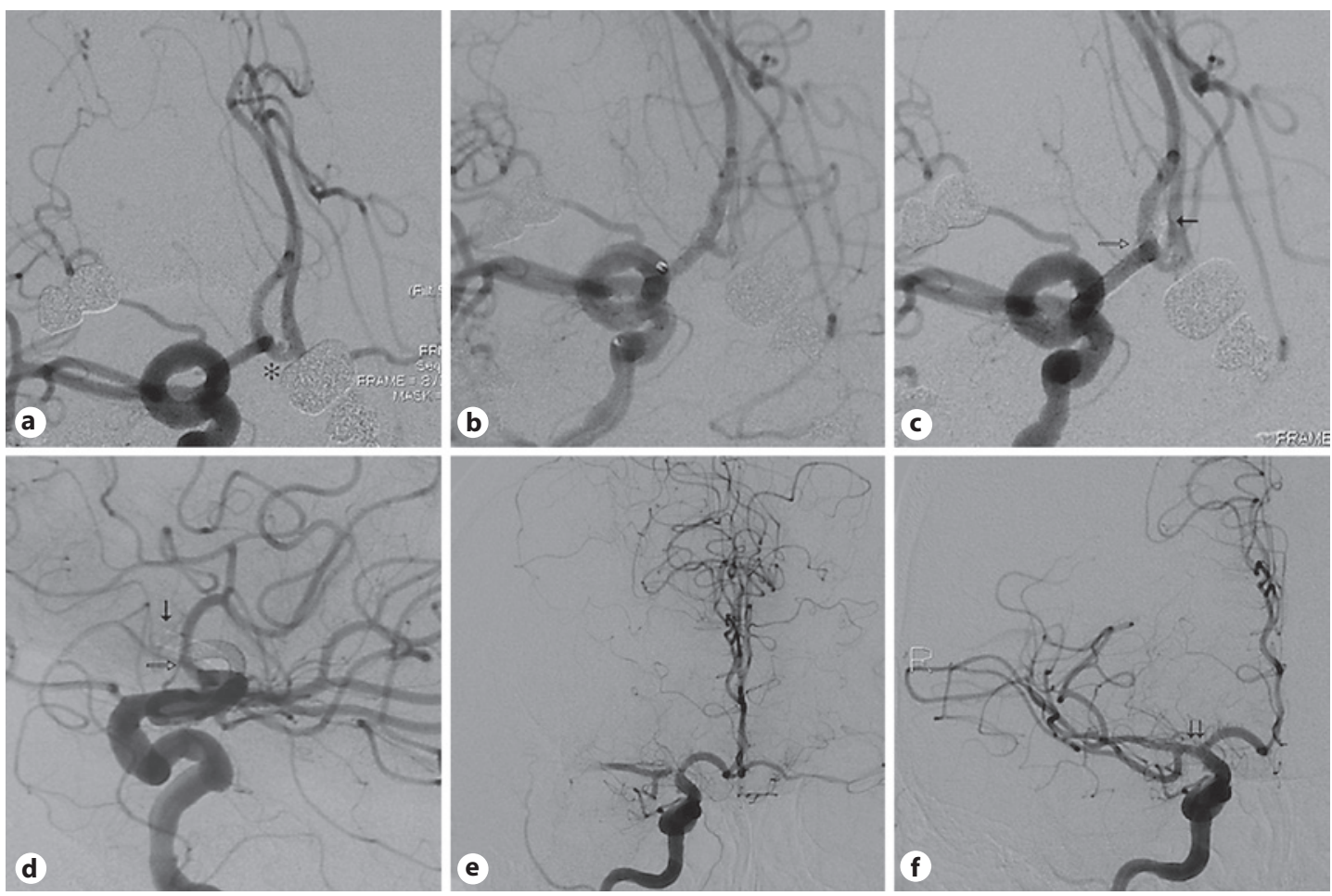

Fig. 2. a Digital subtraction angiogram (DSA) in fontal oblique projection in a patient with subarachnoid hemorrhage shows a blister-like aneurysm at the anterior communicating artery (asterisk). b DSA immediately after placement of a Pipeline embolization device (PED) across the A1/A2 junction showing diminished opacification of aneurysm. Subsequent DSA in frontal (c) and lateral (d) views showing migration of the PED with the proximal end displaced into the carotid terminus. Note the mask of the PED showing the original correct position (arrows) compared to the proximally migrated malposition (open arrows). e Thrombus formation on the displaced PED causing occlusion of the right middle cerebral artery (MCA). $f$ Subsequent DSA after mechanical thrombectomy showing recanalization of the MCA, although with persistent malposition of the proximal PED in the carotid terminus (double arrows). Recatheterization attempts, as well as retrieval attempts of the PED, were unsuccessful and the patient sustained scattered right MCA infarction.

the proximal and distal ends of the neck, preferably in a straight segment of the parent artery, to appropriately anchor.

Incomplete or suboptimal device expansion and proximal device migration (Fig. 2) are two of the more common adverse technical events reported with FDS [26, 29, 60, 82, 86-90]. Prolapse of an FDS into the aneurysm sac has also been reported with different frequencies $[59,86,88,91]$. Certain conditions require expeditious and sometimes creative remediation to correct a malposition [92]. A working knowledge of the common intraprocedural technical complications and the appropriate corrective maneuvers is vital for safe and proper deployment.

(1) Incomplete Expansion. The FDS is unsheathed from distal to proximal. Upon deployment, if the distal end of the device is in an undesirable location or configuration, the device can be resheathed, but the catheter and entire delivery system must be removed as a unit. Once the entire device has been unsheathed, however, it cannot be easily extracted. This presents a dilemma when standard deployment maneuvers fail to effectuate full device expansion to match the size of the parent vessel. Advancing and withdrawing the delivery wire and microcatheter together (known as "wagging") to allow for device deployment 
around arterial curvatures, or bumping the proximal end of the device with the microcatheter after deployment, may be sufficient to induce the proximal end of the stent to fully expand [93]. However, these auxiliary techniques may increase the risk of vascular injury $[85,89,92]$, and bumping the stent may cause the entire device to foreshorten and migrate $[60,82,89]$.

Proper FDS opening is coupled to the forward/distal movement of the coil tip. This allows the device to fully expand and appose to the vessel wall. In certain circumstances, mechanical, anatomical, or technical challenges can hinder appropriate FDS opening and vessel wall apposition, resulting in a stretched device. When the coil tip and delivery wire are not able to advance forward, the FDS cannot fully expand and becomes stretched with attempts to deploy the device by a pushing technique. If FDS deployment continuously fails despite standard maneuvers described above, the FDS can be fully unsheathed within a distal intermediate catheter (DIC), as described by Lin et al. [82]. In this technique, the DIC is first advanced over the Marksman to the unopened part of the FDS. The FDS is then fully unsheathed within the DIC, releasing the FDS from the delivery wire. Since the FDS is completely free from the delivery wire, progressive opening of the device becomes independent of the delivery wire distal migration. FDS deployment and opening then proceed with a combination of unsheathing from the DIC and pushing on the Marksman. The DIC and Marksman are intermittently wagged back and forth to facilitate the vessel wall apposition of the FDS [82].

Second-generation PED, named Pipeline Flex (PFED, ev3/Covidien, Irvine, CA, USA) allows resheathing of the device when up to $90 \%$ deployed. The resheathability feature may obviate device removal in certain situations. However, with PFED, proper device opening is still coupled to the forward/distal movement of the delivery wire, and intra-DIC deployment was still employed in 2 cases involving PFED as described by Lin et al. [82].

If adequate apposition of the device with the parent vessel wall has not been achieved with gentle manipulation, "wagging" maneuvers, or intra-DIC deployment, balloon angioplasty should be considered [83]. In the Pipeline for Uncoilable or Failed Aneurysms (PUFS) study, Becske et al. [29] noted "a few instances" in which a suboptimally expanded PED was dilated by balloon angioplasty. In a series of 100 consecutive procedures, Burrows et al. [26] reported incomplete expansion upon initial deployment of the PED in 9\% of cases, 2 of which were treated with balloon angioplasty. Despite the reported instances of success with this approach, this maneuver carries a risk of thrombosis, vessel rupture, and in certain cases, device migration and/or prolapse [44, 94, 95].

When anterograde access of a constricted FDS in the ICA is unsuccessful, balloon expansion may be possible via a retrograde approach. Navarro et al. [60] described a radical salvage technique for failed PED expansion during deployment. In their case, the partially deployed PED was accessed by an Excelsior SL-10 microcatheter (Stryker Neurovascular, Fremont, CA, USA) in a retrograde fashion via contralateral access of the anterior communicating artery. An intracranial exchange was then performed to advance a Hyperform balloon (EV3, Irvine, CA, USA) to the constricted proximal end of the PED, where angioplasty was used to fully open the PED.

(2) Device Migration and Prolapse (Fig. 2). Device migration has been described in $12 \%$ of cases and may be clinically insignificant as long as the aneurysm neck is adequately covered. In cases where migration of the distal-end of an FDS causes prolapse into an aneurysm, resultant flow diversion may be towards the aneurysm dome causing a significantly higher risk of rupture [26]. A significant difference in luminal diameter between inflow and outflow vessels may produce a constant retrograde squeezing force at the distal end of the FDS causing it to "watermelon-seed" backward. If positioned within the vertical position of the ICA, the weight of the device may drag the construct downward. FDS migration may also partially be the result of an "accordion effect," in which a device that was stretched during deployment undergoes more foreshortening than expected [96]. 
FDS migration is best managed by placing additional devices to achieve complete coverage of the aneurysm and divert the blood flow away from the aneurysmal sac. AJ-shaped guidewire is passed through either the proximal or distal end of the migrated stent and navigated directly into the distal ICA. This is followed by further FDS deployment as necessary to cover the aneurysm neck until the parent vessel is reconstructed [96].

If the proximal part of the FDS has migrated into the aneurysmal sac and attempts to recatheterize the FDS have failed, retrograde access of the FDS may be gained from the distal parent vessel through a microwire advanced from either the basilar artery through a posterior communicating artery, or contralaterally through the anterior communicating artery [96, 97].

In cases of intraprocedural FDS migration, maintaining distal access is critical until the entire parent vessel is reconstructed, especially when multiple FDSs are being used. The direct path across the aneurysm neck is certainly desired, but is not always attainable, especially in cases of giant intracranial aneurysms. In such situations, forming a microcatheter loop inside the aneurysm sac ("traversing the dome") may be helpful in achieving purchase in the distal parent artery of the aneurysm [95]. In this technique, the microcatheter is looped within the aneurysm and advanced far into a distal vessel. Then, the microwire is pulled proximal to the loop, and finally the intra-aneurysmal microcatheter loop can be straightened by gently pulling the microcatheter back $[95,98]$. After removing the loop within the aneurysm, and regaining distal purchase, more straightforward treatment of the aneurysm may proceed with further flow diversion.

In some cases, however, despite a remote distal position, the microcatheter may be unstable and impossible to unloop without losing position. In such situations, angioplasty balloons and retrievable stents have been used as adjunctive anchoring tools to unloop a microcatheter in a giant intracranial aneurysm before treatment with an FDS [98-100]. These techniques involve tracking either a stent retriever (ev3, Irvine, CA, USA) or angioplasty balloon around the loop and into the distal intracranial circulation. The device is then deployed, and used to anchor the microcatheter in the distal vessel. The microcatheter can then be retracted, and the loop can be removed without losing purchase within the distal artery [98, 99]. This is sometimes referred to as the "grappling-hook technique" [95]. Finally, endovascular parent vessel deconstruction or surgical ligation, when tolerated, is an alternative strategy to manage FDS migration.

(3) Device Removal. If an FDS cannot be adequately repositioned, it may need to be retrieved so as not to obstruct flow in the parent artery. Salvage techniques include "corking" and "pseudo-corking" for removal of a mal-positioned or stretched FDS. This maneuver traps the partially deployed FDS against the distal microcatheter, and both may be removed concurrently [101]. If the pusher wire is fractured, the pseudo-corking rescue strategy can be used. The DIC is first advanced over the delivery microcatheter until both tips are nearly aligned to provide maximum support to the delivery microcatheter. The delivery microcatheter is then advanced forward to jam into the proximal end of the partially deployed FDS. Afterwards, the delivery microcatheter (with the FDS) is carefully withdrawn into the DIC. Once the delivery microcatheter is inside the DIC, the DIC and delivery microcatheters are withdrawn as a unit with the FDS inside $[82,101]$.

\section{Postprocedural Complications}

Perianeurysmal Edema

Vasogenic edema in the brain parenchyma surrounding aneurysms has been observed on MRI in the setting of both treated and untreated aneurysms. Untreated aneurysms demonstrating this phenomenon tend to be large, partially thrombosed, or both [3, 102-107]. Mural enhancement, which occurs in a minority of treated aneurysms, appears to be an exaggerated 
Interventional

Neurology

Fig. 3. Digital subtraction angiogram (DSA) in frontal (a) and lateral (b) views in a patient with a large fusiform dissecting aneurysm of the anterior cerebral artery (ACA). c After a single Pipeline embolization device (PED) was positioned across the entirety of the neck of the aneurysm, subsequent DSA in mid-arterial phase showed adequate apposition of PED to the parent ACA, as well as aneurysmal stagnation. d Six hours after intervention, head CT of the decompensated patient showed new subarachnoid and intraventricular hemorrhage. The patient subsequently died from intracranial hemorrhage complications.

\begin{tabular}{l|l}
\hline Intervent Neurol 2019;8:38-54 \\
\hline DOI: 10.1159/000489016 & $\begin{array}{l}\text { @ 2018 S. Karger AG, Basel } \\
\text { www.karger.com/ine }\end{array}$ \\
\hline
\end{tabular}
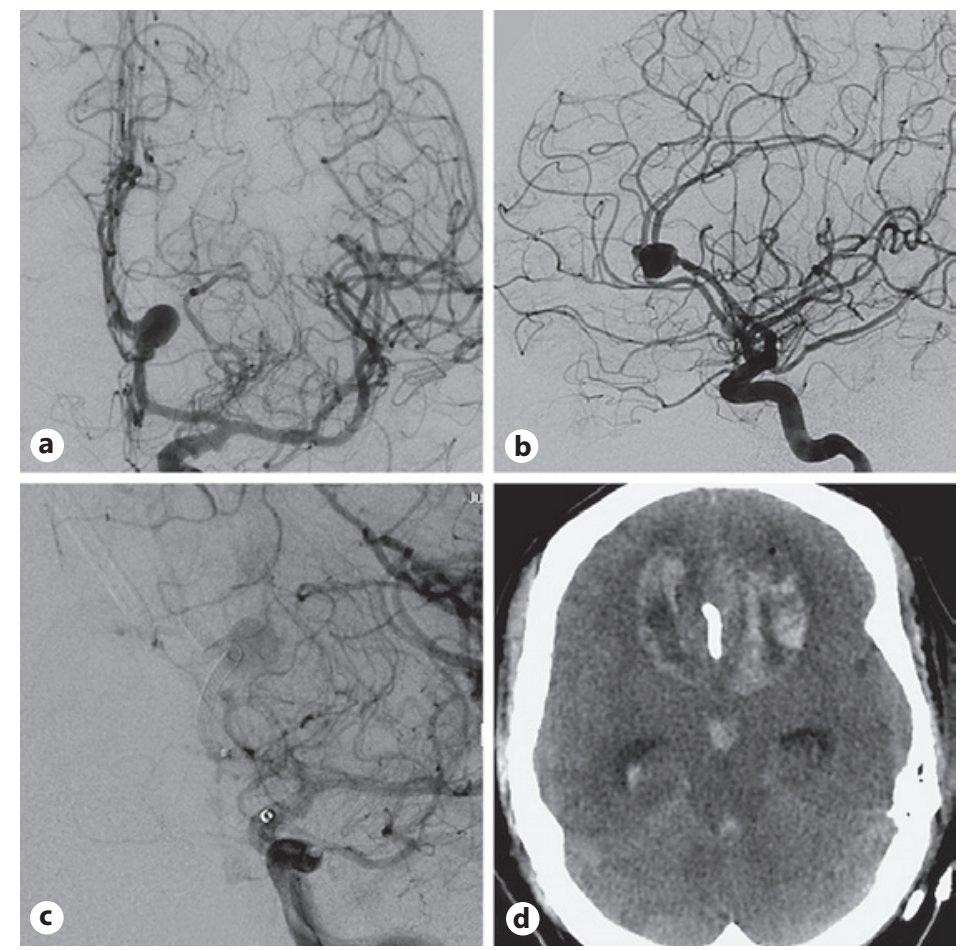

inflammatory healing response that is confined to the aneurysm wall and is asymptomatic $[102,108]$. The etiology is not entirely clear, but it appears to be associated with large aneurysm size and proximity to adjacent brain parenchyma [83]. Aneurysms such as those in the cavernous carotid artery, which are surrounded by dura mater or cerebral spinal fluid, may be less susceptible to the parenchymal extension of the inflammation [83].

Perianeurysmal inflammation and edema may be symptomatic, presenting as an exacerbation of preexisting symptoms related to aneurysmal mass effect, or with new clinical findings, including headache, cranial neuralgia, and visual symptoms [7, 83]. Berge et al. [83] reported on 7 patients with transiently symptomatic perianeurysmal inflammation, vasogenic edema, and blood-brain barrier breakdown after treatment with flow diversion. This clinical deterioration was observed between 3 and 15 days after treatment, and resolved by day 30 .

Symptomatic improvement has been noted following administration of corticosteroids, although no guidelines exist on which patients should receive such therapy [7,83]. Diagnostic and treatment measures may need to address other potentially associated pathology such as hydrocephalus, aseptic or chemical meningitis, and seizures, which have been reported in patients who developed perianeurysmal edema following coil embolization [102, 109-112].

\section{Delayed Complications}

Delayed Hemorrhage

Delayed complications, usually beyond $48 \mathrm{~h}$ after procedure such as intraparenchymal hemorrhage and SAH are critical, and develop in 3 and $4 \%$ of cases, respectively $[57,113]$. Most alarming is distal intraparenchymal hemorrhages that have been reported weeks to months after flow diversion. One recent histopathological review of 3 cases of delayed fatal ipsilateral intraparenchymal hemorrhage following FDS treatment (Fig. 3) demonstrated the presence of foreign material occluding small distal vessels within the hemorrhagic area in all 
patients. Fourier transform infrared spectroscopy demonstrated the presence of polyvinylpyrrolidone in the specimens, a substance that is commonly used for the coating of interventional devices [56, 114].

Perforation with the distal wire of the delivery system of the FDS may explain some hemorrhagic complications (within $48 \mathrm{~h}$ after the procedure) but is unlikely to explain subacute or delayed bleeding. Delayed SAH may occur due to enzymatic degradation of the aneurysm wall during thrombosis $[42,115,116]$. Hemodynamic alteration to flow and altered arterial compliance of the parent vessel by the FDS is also hypothesized to cause delayed hemorrhage [117]. Cerebral infarct with secondary hemorrhagic conversion due to dual antiplatelet therapy has also been suspected as a potential etiology $[117,118]$.

To date, there is no consensus on the management of such delayed hemorrhages. Risks should be weighed between discontinuing antiplatelet therapy to prevent hematoma expansion, and the potential to develop in-stent thrombosis [117]. Whether platelet transfusion, or Desmopressin (DDAVP, arginine vasopressin), should be used to prevent hematoma expansion is unclear. The time of restarting DAPT should be made on a case by case basis.

Delayed Aneurysm Rupture

Delayed aneurysmal rupture is observed primarily in very large and giant symptomatic aneurysms and may be related to intra-aneurysmal thrombosis [26, 29, 68, 116, 119]. Risks associated with delayed rupture are comparable to incidental or intraoperative rupture, and are associated with high morbidity. Despite successful FDS placement, aneurysm rupture occurred in $3.2 \%$ of cases in a series by O'Kelly et al. [120]. There were 3 cases of progressive aneurysm enlargement despite FDS placement. This progression in size corresponded to adverse neurological outcomes [120]. To date, there is no consensus on the management of such delayed rupture, and treatment options may be limited due to restricted intrasaccular access through the wall of the FDS. In a report on a fatal SAH 34 days after successful FDS treatment of a large paraclinoid ICA aneurysm, Ikeda et al. [121] suggest that a hemodynamically unstable period may exist during the process of complete aneurysm thrombosis after flow diversion. During this time, blood pressure management and appropriate antiplatelet therapy may be important.

Delayed Parent Vessel Occlusion

In a case series of 29 patients with 34 aneurysms treated with FDS at 6-month follow-up, $8(33 \%)$ patients had parent vessel stenosis that mostly occurred (5 of 8) when the distal end of the stent was placed within an artery that had a significantly smaller diameter than the proximal artery [122]. Delayed parent vessel occlusion was observed in 5 cases by Becske et al. [29] at 1-year follow-up. One case was "definitively related to noncompliance with antiplatelet medication." The degree of antiplatelet effectiveness was not routinely evaluated in these cases, but such monitoring could be useful to reduce this complication. Endoluminal stenosis of a flow-diverting device may be treated with angioplasty [123].

\section{Conclusions}

Flow diversion has revolutionized endovascular management of previously challenging aneurysms. Complications occur due to thromboembolic events or technical issues related to device placement, vessel rupture, occlusion of side branches and delayed complications such as hemorrhage and aneurysm rupture. Given that these devices are relatively new in the management of these complex aneurysms, the rate and management of complications is just beginning to be understood. 


\section{Disclosure Statement}

All authors have no conflict of interest.

\section{References}

1 Shapiro M, Becske T, Sahlein D, Babb J, Nelson PK: Stent-supported aneurysm coiling: a literature survey of treatment and follow-up. AJNR Am J Neuroradiol 2012;33:159-163.

2 Coley S, Sneade M, Clarke A, Mehta Z, Kallmes D, Cekirge S, Saatci I, Roy D, Molyneux A: Cerecyte coil trial: procedural safety and clinical outcomes in patients with ruptured and unruptured intracranial aneurysms. AJNR Am J Neuroradiol 2012;33:474-480.

3 White PM, Lewis SC, Gholkar A, Sellar RJ, Nahser H, Cognard C, Forrester L, Wardlaw JM: Hydrogel-coated coils versus bare platinum coils for the endovascular treatment of intracranial aneurysms (HELPS): a randomised controlled trial. Lancet 2011;377:1655-1662.

4 Piotin M, Pistocchi S, Bartolini B, Blanc R: Intracranial aneurysm coiling with PGLA-coated coils versus bare platinum coils: long-term anatomic follow-up. Neuroradiology 2012;54:345-348.

5 Szikora I, Berentei Z, Kulcsar Z, Marosfoi M, Vajda ZS, Lee W, Berez A, Nelson PK: Treatment of intracranial aneurysms by functional reconstruction of the parent artery: the Budapest experience with the pipeline embolization device. AJNR Am J Neuroradiol 2010;31:1139-1147.

6 Lylyk P, Miranda C, Ceratto R, Ferrario A, Scrivano E, Luna HR, Berez AL, Tran Q, Nelson PK, Fiorella D: Curative endovascular reconstruction of cerebral aneurysms with the pipeline embolization device: the Buenos Aires experience. Neurosurgery 2009;64:632-642; discussion 642-633; quiz N636.

7 Lylyk P, Miranda C, Ceratto R, Ferrario A, Scrivano E, Luna HR, Berez AL, Tran Q, Nelson PK, Fiorella D: Curative endovascular reconstruction of cerebral aneurysms with the pipeline embolization device: the Buenos Aires experience. Neurosurgery 2009;64:632-643.

8 Skukalek SL, Winkler AM, Kang J, Dion JE, Cawley CM, Webb A, Dannenbaum MJ, Schuette AJ, Asbury B, Tong FC: Effect of antiplatelet therapy and platelet function testing on hemorrhagic and thrombotic complications in patients with cerebral aneurysms treated with the pipeline embolization device: a review and metaanalysis. J Neurointerv Surg 2016;8:58-65.

9 Zanaty M, Chalouhi N, Tjoumakaris SI, Rosenwasser RH, Gonzalez LF, Jabbour P: Flow-diversion panacea or poison? Front Neurol 2014;5:21.

10 Pierot L, Wakhloo AK: Endovascular treatment of intracranial aneurysms current status. Stroke 2013;44: 2046-2054.

11 Canton G, Levy DI, Lasheras JC, Nelson PK: Flow changes caused by the sequential placement of stents across the neck of sidewall cerebral aneurysms. J Neurosurg 2005;103:891-902.

12 Lopes D, Sani S: Histological postmortem study of an internal carotid artery aneurysm treated with the Neuroform stent. Neurosurgery 2005;56:E416; discussion E416.

13 Krishna C, Sonig A, Natarajan SK, Siddiqui AH: The expanding realm of endovascular neurosurgery: flow diversion for cerebral aneurysm management. Methodist DeBakey Cardiovasc J 2014;10:214-219.

14 Nelson PK, Lylyk P, Szikora I, Wetzel SG, Wanke I, Fiorella D: The pipeline embolization device for the intracranial treatment of aneurysms trial. AJNR Am J Neuroradiol 2011;32:34-40.

15 Kadirvel R, Ding YH, Dai D, Rezek I, Lewis DA, Kallmes DF: Cellular mechanisms of aneurysm occlusion after treatment with a flow diverter. Radiology 2014;270:394-399.

16 Becske T, Kallmes DF, Saatci I, McDougall CG, Szikora I, Lanzino G, Moran CJ, Woo HH, Lopes DK, Berez AL, Cher DJ, Siddiqui AH, Levy EI, Albuquerque FC, Fiorella DJ, Berentei Z, Marosfoi M, Cekirge SH, Nelson PK: Pipeline for uncoilable or failed aneurysms: results from a multicenter clinical trial. Radiology 2013;267:858-868.

17 Kallmes DF, Ding YH, Dai D, Kadirvel R, Lewis DA, Cloft HJ: A new endoluminal, flow-disrupting device for treatment of saccular aneurysms. Stroke 2007;38:2346-2352.

18 Yavuz K, Geyik S, Saatci I, Cekirge HS: Endovascular treatment of middle cerebral artery aneurysms with flow modification with the use of the pipeline embolization device. AJNR Am J Neuroradiol 2014;35:529-535.

19 Puffer RC, Kallmes DF, Cloft HJ, Lanzino G: Patency of the ophthalmic artery after flow diversion treatment of paraclinoid aneurysms. J Neurosurg 2012;116:892-896.

20 Liou TM, Li YC: Effects of stent porosity on hemodynamics in a sidewall aneurysm model. J Biomech 2008;41: 1174-1183.

21 Augsburger L, Farhat M, Reymond P, Fonck E, Kulcsar Z, Stergiopulos N, Rufenacht DA: Effect of flow diverter porosity on intraaneurysmal blood flow. Klin Neuroradiol 2009;19:204-214.

22 Lieber BB, Stancampiano AP, Wakhloo AK: Alteration of hemodynamics in aneurysm models by stenting: influence of stent porosity. Ann Biomed Eng 1997;25:460-469.

23 Sadasivan C, Cesar L, Seong J, Rakian A, Hao Q, Tio FO, Wakhloo AK, Lieber BB: An original flow diversion device for the treatment of intracranial aneurysms: evaluation in the rabbit elastase-induced model. Stroke 2009;40:952-958. 
24 Brasiliense LB, Stanley MA, Grewal SS, Cloft HJ, Sauvageau E, Lanzino G, Miller D, Kallmes DF, Hanel R: Silent ischemic events after Pipeline embolization device: a prospective evaluation with MR diffusion-weighted imaging. J Neurointerv Surg 2016;8:1136-1139.

25 Briganti F, Napoli M, Tortora F, Solari D, Bergui M, Boccardi E, Cagliari E, Castellan L, Causin F, Ciceri E: Italian multicenter experience with flow-diverter devices for intracranial unruptured aneurysm treatment with periprocedural complications - a retrospective data analysis. Neuroradiology 2012;54:1145-1152.

26 Burrows AM, Cloft H, Kallmes DF, Lanzino G: Periprocedural and mid-term technical and clinical events after flow diversion for intracranial aneurysms. J Neurointerv Surg 2015;7:646-651.

27 Lall RR, Wong AP, Lall RR, Lawton CD, Smith ZA, Dahdaleh NS: Evidence-based management of deep wound infection after spinal instrumentation. J Clin Neurosci 2015;22:238-242.

28 Tan LA, Keigher KM, Munich SA, Moftakhar R, Lopes DK: Thromboembolic complications with Pipeline Embolization Device placement: impact of procedure time, number of stents and pre-procedure P2Y12 reaction unit (PRU) value. J Neurointerv Surg 2015;7:217-221.

29 Becske T, Kallmes DF, Saatci I, McDougall CG, Szikora I, Lanzino G, Moran CJ, Woo HH, Lopes DK, Berez AL: Pipeline for uncoilable or failed aneurysms: results from a multicenter clinical trial. Radiology 2013;267: 858-868.

30 van Rooij WJ, Sprengers M, de Gast AN, Peluso J, Sluzewski M: 3D rotational angiography: the new gold standard in the detection of additional intracranial aneurysms. AJNR Am J Neuroradiol 2008;29:976-979.

31 Standhardt H, Boecher-Schwarz H, Gruber A, Benesch T, Knosp E, Bavinzski G: Endovascular treatment of unruptured intracranial aneurysms with Guglielmi detachable coils short-and long-term results of a singlecentre series. Stroke 2008;39:899-904.

32 Brilstra EH, Rinkel GJ, van der Graaf Y, van Rooij WJJ, Algra A: Treatment of intracranial aneurysms by embolization with coils a systematic review. Stroke 1999;30:470-476.

33 Kato K, Tomura N, Takahashi S, Sakuma I, Watarai J: Ischemic lesions related to cerebral angiography: evaluation by diffusion weighted MR imaging. Neuroradiology 2003;45:39-43.

34 Krings T, Finney J, Niggemann P, Reinacher P, Lück N, Drexler A, Lovell J, Meyer A, Sehra R, Schauerte P: Magnetic versus manual guidewire manipulation in neuroradiology: in vitro results. Neuroradiology 2006;48: 394-401.

35 Tsantes AE, Ikonomidis I, Papadakis I, Bonovas S, Gialeraki A, Kottaridi C, Kyriakou E, Kokori S, Douramani P, Kopterides P, Karakitsos P, Lekakis J, Kapsimali V: Impact of the proton pump inhibitors and CYP2C19*2 polymorphism on platelet response to clopidogrel as assessed by four platelet function assays. Thromb Res 2013; 132:e105-e111.

36 Kim BJ, Kwon JY, Jung JM, Lee DH, Kang DW, Kim JS, Kwon SU: Association between silent embolic cerebral infarction and continuous increase of P2Y12 reaction units after neurovascular stenting. J Neurosurg 2014; 121:891-898.

37 Tantry US, Gurbel PA: Antiplatelet drug resistance and variability in response: the role of antiplatelet therapy monitoring. Curr Pharm Des 2013;19:3795-3815.

38 Colley R, Yan B: Genetic determinations of variable responsiveness to clopidogrel and implications for neurointerventional procedures. Interv Neurol 2012;1:22-30.

39 Song YM, Seo DW, Chang GY: MR findings in Hashimoto encephalopathy. AJNR Am J Neuroradiol 2004;25: 807-808.

$40 \mathrm{Ng}$ PP, Phatouros CC, Khangure MS: Use of glycoprotein IIb-IIIa inhibitor for a thromboembolic complication during Guglielmi detachable coil treatment of an acutely ruptured aneurysm. AJNR Am J Neuroradiol 2001; 22:1761-1763.

41 Yi H, Gupta R, Jovin T, Tayal A, Genevro J, Gologorsky Y, Horowitz M: Initial experience with the use of intravenous eptifibatide bolus during endovascular treatment of intracranial aneurysms. AJNR Am J Neuroradiol 2006;27:1856-1860.

42 De Vries J, Boogaarts J, Van Norden A, Wakhloo AK: New generation of flow diverter (Surpass) for unruptured intracranial aneurysms a prospective single-center study in 37 patients. Stroke 2013;44:1567-1577.

43 Cloft HJ, Samuels OB, Tong FC, Dion JE: Use of abciximab for mediation of thromboembolic complications of endovascular therapy. AJNR Am J Neuroradiol 2001;22:1764-1767.

44 Al-Mufti F, Amuluru K, Gandhi CD, Prestigiacomo CJ: Flow diversion for intracranial aneurysm management: a new standard of care. Neurotherapeutics 2016;13:582-589.

45 Dumont TM, Natarajan SK, Eller JL, Mocco J, Kelly WH, Snyder KV, Hopkins LN, Siddiqui AH, Levy EI: Primary stenting for acute ischemic stroke using the Enterprise vascular reconstruction device: early results. J Neurointerv Surg 2014;6:363-372.

46 Abou-Chebl A, Yadav JS, Reginelli JP, Bajzer C, Bhatt D, Krieger DW: Intracranial hemorrhage and hyperperfusion syndrome following carotid artery stenting: risk factors, prevention, and treatment. J Am Coll Cardiol 2004;43:1596-1601.

47 Scarborough RM, Kleiman NS, Phillips DR: Platelet glycoprotein IIb/IIIa antagonists. What are the relevant issues concerning their pharmacology and clinical use? Circulation 1999;100:437-444.

48 Harrigan MR, Deveikis JP: General Considerations for Neurointerventional Procedures. Handbook of Cerebrovascular Disease and Neurointerventional Technique. Berlin, Springer, 2013, pp 153-185.

49 Altenburg A, Haage P: Antiplatelet and anticoagulant drugs in interventional radiology. Cardiovasc Interv Radiol 2012;35:30-42. 
50 Hähnel S, Schellinger PD, Gutschalk A, Geletneky K, Hartmann M, Knauth M, Sartor K: Local intra-arterial fibrinolysis of thromboemboli occurring during neuroendovascular procedures with recombinant tissue plasminogen activator. Stroke 2003;34:1723-1728.

51 Cronqvist M, Pierot L, Boulin A, Cognard C, Castaings L, Moret J: Local intraarterial fibrinolysis of thromboemboli occurring during endovascular treatment of intracerebral aneurysm: a comparison of anatomic results and clinical outcome. AJNR Am J Neuroradiol 1998;19:157-165.

52 Song JK, Niimi Y, Fernandez PM, Brisman JL, Buciuc R, Kupersmith MJ, Berenstein A: Thrombus formation during intracranial aneurysm coil placement: treatment with intra-arterial abciximab. AJNR Am J Neuroradiol 2004;25:1147-1153.

53 Yu SC-H, Kwok C-K, Cheng P-W, Chan K-Y, Lau SS, Lui W-M, Leung K-M, Lee R, Cheng HK-M, Cheung Y-L: Intracranial aneurysms: midterm outcome of pipeline embolization device - a prospective study in 143 patients with 178 aneurysms. Radiology 2012;265:893-901.

54 Szikora I, Berentei Z, Kulcsar Z, Marosfoi M, Vajda Z, Lee W, Berez A, Nelson PK: Treatment of intracranial aneurysms by functional reconstruction of the parent artery: the Budapest experience with the pipeline embolization device. AJNR Am J Neuroradiol 2010;31:1139-1147.

55 Chalouhi N, Starke RM, Yang S, Bovenzi CD, Tjoumakaris S, Hasan D, Gonzalez LF, Rosenwasser R, Jabbour P: Extending the indications of flow diversion to small, unruptured, saccular aneurysms of the anterior circulation. Stroke 2014;45:54-58.

56 D’Urso PI, Lanzino G, Cloft HJ, Kallmes DF: Flow diversion for intracranial aneurysms a review. Stroke 2011; 42:2363-2368.

57 Starke RM, Turk A, Ding D, Crowley RW, Liu KC, Chalouhi N, Hasan DM, Dumont AS, Jabbour P, Durst CR: Technology developments in endovascular treatment of intracranial aneurysms. J Neurointerv Surg 2016;8:135144.

58 Pistocchi S, Blanc R, Bartolini B, Piotin M: Flow diverters at and beyond the level of the circle of Willis for the treatment of intracranial aneurysms. Stroke 2012;43:1032-1038.

59 Gentric J-C, Fahed R, Darsaut TE, Salazkin I, Roy D, Raymond J: Fatal arterial rupture during angioplasty of a flow diverter in a recurrent, previously Y-stented giant MCA bifurcation aneurysm. Interv Neuroradiol 2016; 22:278-286.

60 Navarro R, Yoon J, Dixon T, Miller DA, Hanel RA, Tawk RG: Retrograde trans-anterior communicating artery rescue of unopened Pipeline Embolization Device with balloon dilation: complication management. BMJ Case Rep 2014;2014:bcr2013011009.

61 Krings T, Geibprasert S, ter Brugge KG: Case-Based Interventional Neuroradiology. Stuttgart, Thieme, 2011.

62 Mitsos AP: Endovascular Neurosurgery Through Clinical Cases. Berlin, Springer, 2015.

63 Butcher K, Laidlaw J: Current intracerebral haemorrhage management. J Clin Neurosci 2003;10:158-167.

64 Willinsky R: Use of a second microcatheter in the management of a perforation during endovascular treatment of a cerebral aneurysm. AJNR Am J Neuroradiol 2000;21:1537-1539.

65 Lin LM, Colby GP, Jiang B, Pero G, Boccardi E, Coon AL: Transvenous approach for the treatment of direct carotid cavernous fistula following Pipeline embolization of cavernous carotid aneurysm: a report of two cases and review of the literature. J Neurointerv Surg 2015; 7:e30.

66 Mustafa W, Kadziolka K, Anxionnat R, Pierot L: Direct carotid-cavernous fistula following intracavernous carotid aneurysm treatment with a flow-diverter stent. A case report. Interv Neuroradiol 2010;16:447-450.

67 Kulcsar Z, Houdart E, Bonafe A, Parker G, Millar J, Goddard AJ, Renowden S, Gal G, Turowski B, Mitchell K, Gray F, Rodriguez M, van den Berg R, Gruber A, Desal H, Wanke I, Rufenacht DA: Intra-aneurysmal thrombosis as a possible cause of delayed aneurysm rupture after flow-diversion treatment. AJNR Am J Neuroradiol 2011;32: $20-25$.

68 Park MS, Albuquerque FC, Nanaszko M, Sanborn MR, Moon K, Abla AA, McDougall CG: Critical assessment of complications associated with use of the Pipeline Embolization Device. J Neurointerv Surg 2015;7:652-659.

69 Amuluru K, Al-Mufti F, Gandhi CD, Prestigiacomo CJ, Singh IP: Direct carotid-cavernous fistula: a complication of, and treatment with, flow diversion. Interv Neuroradiol 2016;22:569-576.

70 Gemmete JJ, Chaudhary N, Pandey A, Ansari S: Treatment of carotid cavernous fistulas. Curr Treat Options Neurol 2010;12:43-53.

71 Nadarajah M, Power M, Barry B, Wenderoth J: Treatment of a traumatic carotid-cavernous fistula by the sole use of a flow diverting stent. J Neurointerv Surg 2012;4:e1.

72 Iancu D, Lum C, Ahmed ME, Glikstein R, Dos Santos MP, Lesiuk H, Labib M, Kassam AB: Flow diversion in the treatment of carotid injury and carotid-cavernous fistula after transsphenoidal surgery. Interv Neuroradiol 2015;21:346-350.

73 Pradeep N, Nottingham R, Kam A, Gandhi D, Razack N: Treatment of post-traumatic carotid-cavernous fistulas using pipeline embolization device assistance. J Neurointerv Surg 2016;8:e40.

74 Nossek E, Zumofen D, Nelson E, Raz E, Potts MB, Desousa KG, Tanweer O, Shapiro M, Becske T, Riina HA: Use of Pipeline Embolization Devices for treatment of a direct carotid-cavernous fistula. Acta Neurochir 2015;157: 1125-1129; discussion 1130.

75 Meyers PM, Thakur GA, Tomsick TA: Temporary endovascular balloon occlusion of the internal carotid artery with a nondetachable silicone balloon catheter: analysis of technique and cost. AJNR Am J Neuroradiol 1999; 20:559-564. 
76 Nelson PK, Lylyk P, Szikora I, Wetzel S, Wanke I, Fiorella D: The pipeline embolization device for the intracranial treatment of aneurysms trial. AJNR Am J Neuroradiol 2011;32:34-40.

77 Kocer N, Kizilkilic O, Albayram S, Adaletli I, Kantarci F, Islak C: Treatment of iatrogenic internal carotid artery laceration and carotid cavernous fistula with endovascular stent-graft placement. AJNR Am J Neuroradiol 2002;23:442-446.

78 Cloft HJ, Jensen ME, Kallmes DF, Dion JE: Arterial dissections complicating cerebral angiography and cerebrovascular interventions. AJNR Am J Neuroradiol 2000;21:541-545.

79 Fischer S, Vajda Z, Perez MA, Schmid E, Hopf N, Bäzner H, Henkes H: Pipeline embolization device (PED) for neurovascular reconstruction: initial experience in the treatment of 101 intracranial aneurysms and dissections. Neuroradiology 2012;54:369-382.

80 Brzezicki G, Rivet DJ, Reavey-Cantwell J: Pipeline Embolization Device for treatment of high cervical and skull base carotid artery dissections: clinical case series. J Neurointerv Surg 2016;8:722-728.

81 Amenta P, Starke R, Jabbour P, Tjoumakaris S, Gonzalez L, Rosenwasser R, Pribitkin E, Dumont A: Successful treatment of a traumatic carotid pseudoaneurysm with the Pipeline stent: case report and review of the literature. Surg Neurol Int 2012;3:160.

82 Lin L-M, Colby GP, Jiang B, Nundkumar N, HuangJ, Tamargo RJ, Coon AL: Intra-DIC (distal intracranial catheter) deployment of the Pipeline embolization device: a novel rescue strategy for failed device expansion. J Neurointerv Surg 2016;8:840-846.

83 Berge J, Tourdias T, Moreau J-F, Barreau X, Dousset V: Perianeurysmal brain inflammation after flow-diversion treatment. AJNR Am J Neuroradiol 2011;32:1930-1934.

84 Lin L-M, Colby GP, Jiang B, Uwandu C, Huang J, Tamargo RJ, Coon AL: Classification of cavernous internal carotid artery tortuosity: a predictor of procedural complexity in Pipeline embolization. J Neurointerv Surg 2015; 7:628-633.

85 Jabbour P, Chalouhi N, Tjoumakaris S, Gonzalez LF, Dumont AS, Randazzo C, Starke RM, Hasan D, Chitale R, Singhal S: The Pipeline Embolization Device: learning curve and predictors of complications and aneurysm obliteration. Neurosurgery 2013;73:113-120.

86 Crowley RW, Ducruet AF, McDougall CG, Albuquerque FC: Endovascular advances for brain arteriovenous malformations. Neurosurgery 2014;74:S74-S82.

87 Martínez-Galdámez M, Pérez S, Vega A, Ruiz P, Caniego J, Bárcena E, Saura P, Méndez J, Delgado F, OrtegaGutierrez S: Endovascular treatment of intracranial aneurysms using the Pipeline Flex embolization device: a case series of 30 consecutive patients. J Neurointerv Surg 2016;8:396-401.

88 Pereira VM, Brina O, Delattre BM, Ouared R, Bouillot P, Erceg G, Schaller K, Lovblad K-O, Vargas M-I: Assessment of intra-aneurysmal flow modification after flow diverter stent placement with four-dimensional flow MRI: a feasibility study. J Neurointerv Surg 2015;7:913-919.

89 Miller TR, Jindal G, Gandhi D: Focal, transient mechanical narrowing of a pipeline embolization device following treatment of an internal carotid artery aneurysm. J Neurointerv Surg 2015;7:e35.

90 Colby GP, Lin L-M, Gomez JF, Paul AR, Huang J, Tamargo RJ, Coon AL: Immediate procedural outcomes in 35 consecutive pipeline embolization cases: a single-center, single-user experience. J Neurointerv Surg 2013;5: 237-246.

91 Hauck EF, Natarajan SK, Langer DJ, Hopkins LN, Siddiqui AH, Levy EI: Retrograde trans-posterior communicating artery snare-assisted rescue of lost access to a foreshortened pipeline embolization device: complication management. Neurosurgery 2010;67:(suppl operative):495-502.

92 Park MS, Albuquerque FC, Nanaszko M, Sanborn MR, Moon K, Abla AA, McDougall CG: Critical assessment of complications associated with use of the Pipeline Embolization Device. J Neurointerv Surg 2015;7:652-659.

93 Le EJ, Miller T, Serulle Y, Shivashankar R, Jindal G, Gandhi D: Use of Pipeline Flex is associated with reduced fluoroscopy time, procedure time, and technical failure compared with the first-generation Pipeline embolization device. J Neurointerv Surg DOI: 10.1136/neurintsurg-2016-012261.

94 Alderazi YJ, Shastri D, Kass-Hout T, Prestigiacomo CJ, Gandhi CD: Flow diverters for intracranial aneurysms. Stroke Res Treat 2014;2014.

95 Crowley RW, Abla AA, Ducruet AF, McDougall CG, Albuquerque FC: Novel application of a balloon-anchoring technique for the realignment of a prolapsed pipeline embolization device: a technical report. J Neurointerv Surg 2014;6:439-444.

96 Chalouhi N, Tjoumakaris SI, Gonzalez LF, Hasan D, Pema PJ, Gould G, Rosenwasser RH, Jabbour PM: Spontaneous delayed migration/shortening of the pipeline embolization device: report of 5 cases. AJNR Am J Neuroradiol 2013;34:2326-2330.

97 Hauck EF, Natarajan SK, Langer DJ, Hopkins LN, Siddiqui AH, Levy EI: Retrograde trans-posterior communicating artery snare-assisted rescue of lost access to a foreshortened pipeline embolization device: complication management. Neurosurgery 2010;67:495-502.

98 Clarencon F, Wyse G, Fanning N, Di Maria F, Gaston A, Chiras J, Sourour N: Solitaire FR stent as an adjunctive tool for pipeline stent deployment in the treatment of giant intracranial aneurysms. Neurosurgery 2013; 72:onsE241-E244; discussion onsE244.

99 Fargen KM, Velat GJ, Lawson MF, Hoh BL, Mocco J: The stent anchor technique for distal access through a large or giant aneurysm. J Neurointerv Surg 2013;5:e24.

100 Snyder KV, Natarajan SK, Hauck EF, Mocco J, Siddiqui AH, Hopkins LN, Levy EI: The balloon anchor technique: a novel technique for distal access through a giant aneurysm. J Neurointerv Surg 2010;2:363-367. 
101 Colby GP, Gomez JF, Lin LM, Paul AR, Coon AL: In situ removal of the pipeline embolization device: the "corking" and "pseudo-corking" techniques. J Neurointerv Surg 2013;5:e6.

102 Fanning NF, Willinsky RA, ter Brugge KG: Wall enhancement, edema, and hydrocephalus after endovascular coil occlusion of intradural cerebral aneurysms. J Neurosurg 2008;108:1074-1086.

103 Craven I, Patel U, Gibson A, Coley S: Symptomatic perianeurysmal edema following bare platinum embolization of a small unruptured cerebral aneurysm. AJNR Am J Neuroradiol 2009;30:1998-2000.

104 Jeon P, Kim B, Kim D, Park S, Kim K, Kim D, Suh S, Huh S, Kim Y: Reconstructive endovascular treatment of fusiform or ultrawide-neck circumferential aneurysms with multiple overlapping enterprise stents and coiling. AJNR Am J Neuroradiol 2012;33:965-971.

105 Dang LV, Aggour M, Thiriaux A, Kadziolka K, Pierot L: Post-embolization perianeurysmal edema revealed by temporal lobe epilepsy in a case of unruptured internal carotid artery aneurysm treated with bare platinum coils. J Neuroradiol 2009;36:298-300.

106 Hammoud D, Gailloud P, Olivi A, Murphy KJ: Acute vasogenic edema induced by thrombosis of a giant intracranial aneurysm: a cause of pseudostroke after therapeutic occlusion of the parent vessel. AJNR Am J Neuroradiol 2003;24:1237-1239.

107 Hampton T, Walsh D, Tolias C, Fiorella D: Mural destabilization after aneurysm treatment with a flow-diverting device: a report of two cases. J Neurointerv Surg 2011;3:167-171.

108 Tulamo R, Frösen J, Hernesniemi J, Niemelä M: Inflammatory changes in the aneurysm wall: a review. J Neurointerv Surg 2010;2:120-130.

109 Meyers PM, Lavine SD, Fitzsimmons B-F, Commichau C, Parra A, Mayer SA, Solomon RA, Connolly ES Jr: Chemical meningitis after cerebral aneurysm treatment using two second-generation aneurysm coils: report of two cases. Neurosurgery 2004;55:1222.

110 Horie N, Kitagawa N, Morikawa M, Tsutsumi K, Kaminogo M, Nagata I: Progressive perianeurysmal edema induced after endovascular coil embolization: report of three cases and review of the literature. J Neurosurg 2007;106:916-920.

111 White J, Layton K, Evans A, Tong F, Jensen M, Kallmes DF, Dion J, Cloft HJ: Transorbital puncture for the treatment of cavernous sinus dural arteriovenous fistulas. AJNR Am J Neuroradiol 2007;28:1415-1417.

112 Cohen JE, Moscovici S, Itshayek E: The advantages of balloon assistance in endovascular embolization of spinal dural arteriovenous fistulas. J Clin Neurosci 2013;20:141-143.

113 Brinjikji W, Murad MH, Lanzino G, Cloft HJ, Kallmes DF: Endovascular treatment of intracranial aneurysms with flow diverters: a meta-analysis. Stroke 2013;44:442-447.

114 Hu YC, Deshmukh VR, Albuquerque FC, Fiorella D, Nixon RR, Heck DV, Barnwell SL, McDougall CG: Histopathological assessment of fatal ipsilateral intraparenchymal hemorrhages after the treatment of supraclinoid aneurysms with the Pipeline Embolization Device: report of 3 cases. J Neurosurg 2014;120:365-374.

115 Turowski B, Macht S, Kulcsar Z, Hanggi D, Stummer W: Early fatal hemorrhage after endovascular cerebral aneurysm treatment with a flow diverter (SILK-Stent): do we need to rethink our concepts? Neuroradiology 2011;53:37-41.

116 Kulcsár Z, Houdart E, Bonafe A, Parker G, Millar J, Goddard A, Renowden S, Gal G, Turowski B, Mitchell K: Intraaneurysmal thrombosis as a possible cause of delayed aneurysm rupture after flow-diversion treatment. AJNR Am J Neuroradiol 2011;32:20-25.

117 Cruz J, Chow M, O’Kelly C, Marotta B, Spears J, Montanera W, Fiorella D, Marotta T: Delayed ipsilateral parenchymal hemorrhage following flow diversion for the treatment of anterior circulation aneurysms. AJNR Am J Neuroradiol 2012;33:603-608.

118 Colby GP, Lin LM, Coon AL: Revisiting the risk of intraparenchymal hemorrhage following aneurysm treatment by flow diversion. AJNR Am J Neuroradiol 2012;33:E107; author reply E108.

119 Siddiqui AH, Abla AA, Kan P, Dumont TM, Jahshan S, Britz GW, Hopkins LN, Levy EI: Panacea or problem: flow diverters in the treatment of symptomatic large or giant fusiform vertebrobasilar aneurysms: clinical article. J Neurosurg 2012;116:1258-1266.

120 O’Kelly C, Spears J, Chow M, Wong J, Boulton M, Weill A, Willinsky R, Kelly M, Marotta T: Canadian experience with the pipeline embolization device for repair of unruptured intracranial aneurysms. AJNR Am J Neuroradiol 2013;34:381-387.

121 Ikeda H, Ishii A, Kikuchi T, Ando M, Chihara H, Arai D, Hattori E, Miyamoto S: Delayed aneurysm rupture due to residual blood flow at the inflow zone of the intracranial paraclinoid internal carotid aneurysm treated with the Pipeline embolization device: histopathological investigation. Interv Neuroradiol 2015;21:674-683.

122 Lubicz B, Collignon L, Raphaeli G, Pruvo JP, Bruneau M, De Witte O, Leclerc X: Flow-diverter stent for the endovascular treatment of intracranial aneurysms: a prospective study in 29 patients with 34 aneurysms. Stroke 2010;41:2247-2253.

123 Estrade L, Makoyeva A, Darsaut TE, Ghostine J, Kouznetsov E, Salazkin I, Roy D, Weill A, Raymond J: In vitro reproduction of device deformation leading to thrombotic complications and failure of flow diversion. Interv Neuroradiol 2013;19:432-437. 